\title{
Sales and Sincerity: The Role of Relational Framing in Word-of-Mouth Marketing
}

\author{
Mirjam A. Tuk, Peeter W.J. Verlegh, Ale Smidts \\ and Daniel H.J. Wigboldus
}

Accepted for publication in the Journal of Consumer Psychology

\begin{tabular}{|l|l|}
\hline \multicolumn{2}{|l|}{ ERIM REPORT SERIES RESEARCH IN MANAGEMENT } \\
\hline ERIM Report Series reference number & ERS-2008-056-MKT \\
\hline Publication & September 2008 \\
\hline Number of pages & 38 \\
\hline Persistent paper URL & http://hdl.handle.net/1765/13183 \\
\hline Email address corresponding author & m.a.tuk@rug.nl \\
\hline Address & Erasmus Research Institute of Management (ERIM) \\
& RSM Erasmus University / Erasmus School of Economics \\
& Erasmus Universiteit Rotterdam \\
& P.O.Box 1738 \\
& 3000 DR Rotterdam, The Netherlands \\
& Phone: + 31 10 408 1182 \\
& Fax: $\quad+31104089640$ \\
& Email: info@erim.eur.nl \\
& Internet: www.erim.eur.nl \\
\hline
\end{tabular}

Bibliographic data and classifications of all the ERIM reports are also available on the ERIM website: www.erim.eur.nl 


\section{ERASMUS RESEARCH INSTITUTE OF MANAGEMENT}

\section{REPORT SERIES}

\section{RESEARCH IN MANAGEMENT}

\begin{tabular}{|c|c|}
\hline \multicolumn{2}{|c|}{ ABSTRACT AND KEYWORDS } \\
\hline Abstract & $\begin{array}{l}\text { In the current research, we study relationship norms in a word-of-mouth marketing context. The } \\
\text { presence of a financial incentive for a recommendation implies that the word-of-mouth behavior } \\
\text { may be driven by ulterior motives. This setting triggers both friendship (Equality Matching; EM) } \\
\text { and sales (Market Pricing; MP) relationship norms. However, the evaluation of the } \\
\text { recommendation depends crucially on the relationship norm activated during the interaction. We } \\
\text { show that, compared to MP relationship norms, activating EM norms leads to less sincere agent } \\
\text { evaluations, but at the same time to higher intentions to comply with the target offer. We show } \\
\text { that these norms can be activated outside awareness and influence our evaluations of } \\
\text { interaction partners in a cognitively efficient manner. A second study shows that disclosing the } \\
\text { financial motive has a positive effect on agent evaluations, but only when the recommendation } \\
\text { target can devote full attention to the interaction. }\end{array}$ \\
\hline Free Keywords & word-of-mouth, rewarded recommendations, relationship norms, disclosure of ulterior motive \\
\hline Availability & $\begin{array}{l}\text { The ERIM Report Series is distributed through the following platforms: } \\
\text { Academic Repository at Erasmus University (DEAR), DEAR ERIM Series Portal } \\
\text { Social Science Research Network (SSRN), SSRN ERIM Series Webpage } \\
\text { Research Papers in Economics (REPEC), REPEC ERIM Series Webpage }\end{array}$ \\
\hline Classifications & $\begin{array}{l}\text { The electronic versions of the papers in the ERIM report Series contain bibliographic metadata } \\
\text { by the following classification systems: } \\
\text { Library of Congress Classification, (LCC) LCC Webpage } \\
\text { Journal of Economic Literature, (JEL), JEL Webpage } \\
\text { ACM Computing Classification System CCS Webpage } \\
\text { Inspec Classification scheme (ICS), ICS Webpage }\end{array}$ \\
\hline
\end{tabular}


Running head: RELATIONAL FRAMING IN WORD-OF-MOUTH MARKETING

\title{
SALES AND SINCERITY:
}

THE ROLE OF RELATIONAL FRAMING IN WORD-OF-MOUTH MARKETING

Manuscript accepted for publication in the Journal of Consumer Psychology.

\author{
Mirjam A. Tuk \\ University of Groningen
}

Peeter W.J. Verlegh \& Ale Smidts

Rotterdam School of Management, Erasmus University Rotterdam

Daniel H.J. Wigboldus

Radboud University Nijmegen

Author Note

Mirjam A. Tuk, Department of Marketing, University of Groningen, Groningen, The Netherlands; Peeter W. J. Verlegh \& Ale Smidts, Department of Marketing Management, Rotterdam School of Management, Erasmus University Rotterdam, The Netherlands; Daniel H. J. Wigboldus, Behavioural Science Institute, Radboud University Nijmegen, Nijmegen, The Netherlands.

This research was supported by the Erasmus Research Institute of Management (ERIM).

Correspondence concerning this article should be addressed to, Mirjam A. Tuk, Department of Marketing, University of Groningen, P.O. Box 800, 9700 AV, Groningen, The Netherlands. E-mail: m.a.tuk@rug.nl 


\begin{abstract}
In the current research, we study relationship norms in a word-of-mouth marketing context. The presence of a financial incentive for a recommendation implies that the word-of-mouth behavior may be driven by ulterior motives. This setting triggers both friendship (Equality Matching; EM) and sales (Market Pricing; MP) relationship norms. However, the evaluation of the recommendation depends crucially on the relationship norm activated during the interaction. We show that, compared to MP relationship norms, activating EM norms leads to less sincere agent evaluations, but at the same time to higher intentions to comply with the target offer. We show that these norms can be activated outside awareness and influence our evaluations of interaction partners in a cognitively efficient manner. A second study shows that disclosing the financial motive has a positive effect on agent evaluations, but only when the recommendation target can devote full attention to the interaction.
\end{abstract}


Sales and sincerity:

Buzz marketing has become an increasingly popular marketing tactic, in which the focus is on stimulating word-of-mouth by (financially) rewarding the referring customer (Rosen, 2000). Although financial rewards increase referral likelihood (Ryu \& Feick, 2007), they also entail a social risk. Financial rewards introduce an ulterior motive for providing a referral, which may result in skepticism on the part of the receiving consumer (e.g., Godes et al., 2005; Godin, 2002 p. 95-96). Indeed, a recent poll indicates that consumers are unlikely to trust recommendations from a friend if that friend had previously referred products in return for a reward (Shin, 2006).

Although buzz marketing has become standard fare for marketers, it is not uncontroversial. Its popularity led consumers' advocacy groups to petition the Federal Trade Commission (FTC), which in response stressed the fact that referrals from "buzzing" customers should be accompanied by a proper disclosure. Marketers have varying opinions about this. On the one hand, the Word-of-Mouth Marketing Association (WOMMA) has included this policy in their ethics code (http://www.womma.org/ethics/code/read/), and even proposed to make non-disclosure a criminal offense (WOMMA press release of April 18, 2008). On the other hand, several companies have expressed fears that disclosures undermine the value of buzz marketing (see Creamer, 2005; Shin, 2006 for discussions).

The controversy around buzz marketing arises from its' ambiguous nature. Like regular forms of word of mouth, it involves a friendly exchange of product- or servicerelated information among consumers. However, in addition, the use of (financial) rewards introduces a 'sales' aspect. Theories on interpersonal relations indicate that 
"friendship" and "sales" relationships differ in terms of the behaviors that are perceived as acceptable (see Aggarwal, 2004; Fiske, 1992; Folkes, 2002; Grayson, 2007; McGraw, Tetlock, \& Kristel, 2003). In the current research, we examine the impact of these relationship norms on consumers' responses towards rewarded referrals and the referring agent, and provide insight into the process that underlies these responses. We argue that relationship norms can impact consumers' perceptions of their interaction partners, even when they are activated outside awareness and separate from the target interaction. Furthermore, in order to gain insights in the impact of disclosures and in the impact of relationship norms, we examine the impact of disclosing or not disclosing the commercial motives. To summarize, with the current research, we contribute to the literature on relationship norms within consumer behavior by examining how these norms influence perceptions of interaction partners, and we gain more insight in important psychological mechanisms (relationship norms and disclosures) involved in buzz marketing. Interpersonal influence in different types of relationships

Theories like the Elaboration Likelihood Model or the Heuristic-Systematic Model (for a review, see Petty \& Wegener, 1998), and work within the persuasion knowledge area (e.g., Ahluwalia \& Burnkant, 2004; DeCarlo, 2005; Friestad \& Wright, 1994; Campbell \& Kirmani, 2008; Priester \& Petty, 2003; Reinhard, Messner \& Sporer, 2006) provide important insights into the impact of persuasion agent, message, and target characteristics on the effectiveness of persuasion attempts. Less attention has been given to the impact of different relationships that can exist between persuasion agent and target, and how norms that are valid within specific relationships influence the effectiveness of the persuasion attempt. Word-of-mouth referrals are common among friends and 
acquaintances, but advice in return for a financial reward fits better with the norms applicable to sales interactions (Fiske, 1992). The question that arises is how the norms that are related to these different relationships influence persuasion attempts.

Folkes (2002, p. 1) pointed out: “....when situational cues lead people to perceive themselves as customers, they then interpret the world differently than when they do not perceive themselves as customers, and that influences their behavior." But what exactly makes the salesperson-customer relationship different and unique? Fiske's (1992) theory of social relationships is highly relevant to this question. Fiske argues that people in all cultures use four types of relational models to govern their social interaction, evaluation, and affect towards others. The first type is communal sharing (CS), in which there is a bounded group of people equivalent to each other, as within a family. The second type is authority ranking (AR), which entails an ordinal ranking of the social world. One's rank determines one's status and who has to obey who, as within military rankings. The third type is equality matching (EM), in which balance is important. Individuals keep track of favors given and received, and try to balance this. EM relations are common among acquaintances, colleagues, and classmates. The fourth relationship type is market pricing (MP), in which people use a single value or utility metric (usually money) to make ratio comparisons of the costs and benefits of exchanges. There is usually one relationship type dominant within an interaction (Fiske, 1992).

Research on how these relationships influence the perception of consumer behavior is limited, but there are parallels with work by Thaler (1985), and McGraw and colleagues (Aggarwal, 2004; McGraw \& Tetlock, 2005; McGraw et al., 2003). This research examined how exchange behavior is influenced by social relationships. Thaler 
showed that consumers ask fairer (lower) selling prices when they sell goods to friends. McGraw and Tetlock (2005, Study 2) showed that the desire to maximize profit is higher within MP relations than within EM, AR or CS relations (which did not differ significantly on any of these variables). Furthermore, both selling prices (measured as the willingness to pay) and the willingness to accept for products, was higher in MP relations than in any of the other relationships. This indicates that the relationship in which an exchange occurs, partly determines the value of these exchanged objects. The use of financial compensation as exchange currency is an important difference between MP and the other relational types. Heyman and Ariely (2004) only differentiate between MP relationships ("monetary markets") and the other types of relationships ("social markets"), and showed that financial rewards immediately turn social market transactions into monetary market transactions.

Besides influencing the value of objects, relationship norms also influence which types of behaviors are appropriate and acceptable. Violations of the norms that are embedded in the relationship are not appreciated and can lead to conflict between the interaction partners. In line with this, McGraw and Tetlock (2005, Study 3) showed that, within an EM relationship, an MP transaction is less acceptable than an EM transaction. This implies that receiving a financial reward for recommending a product, is more appropriate within an MP relationship than within an EM relationship. However, at the same time, rejecting a recommendation is more common practice within MP relationships than within EM relationships (Kirmani \& Campbell, 2004). People are used to ignore or reject recommendations from salespeople (MP relationship), but not from people with whom they have an EM relationship. 
The automatic nature of relationship norms

An important and yet unanswered question regards the underlying process by which relationship norms influence our perceptions and judgments of the behaviors of our interaction partners. McGraw and Tetlock (2005) mainly manipulated relationship norms by explicitly mentioning the relationship. In response to these studies, Johar (2005; see also Kahn, 2005) suggested that the results might have been caused by a difference in attributional thinking, because certain behaviors fit more within one relationship than within others. This in turn might have caused differences in degree of deliberation needed to make sense of the same behaviors within different relationship types.

We propose that relationship norms guide our interpretations and judgments of the behaviors of our interaction partners on a more automatic level, i.e., without conscious intent or awareness (Bargh, 1994). Previous research showed that the activation of norms related to a certain environment, can have an influence on behaviors (e.g., Cialdini, 2003, 2007). Aarts and Dijksterhuis (2003) showed that people who are exposed to pictures of a library (where the norm is to be silent), tend to lower their voice in a subsequent task. Similarly, Aarts, Dijksterhuis and Custers (2003) demonstrated that activating a conformity norm (by priming respondents with words like comply, obey, and conform) causes people to behave more norm confirming.

The question that arises, is whether relationship norms can become activated outside awareness and have an influence on how we perceive the behavior of others. A crucial difference with the previous research examining norm activation, is the interpersonal nature of relationship norms. Where environmental or situational norms primarily have a impact on the behaviors of the target person, relationship norms have an 
influence on the interpretation of the behaviors of interaction partners. This would show that relationship norms can be activated automatically. Furthermore, this implies that (unobtrusively) activated norms not only exert an influence on an intrapersonal level (norm influence on own behaviors, as the research described above showed) but also on an interpersonal level (norm influence on the perception and judgment of the behavior of interaction partners).

A potential problem that might arise from this way of looking at (unobtrusively) activated relationship norms is that any target interaction will almost inevitably activate relationship norms by itself (Fiske, 1992). While there might be ambiguity with regard to which relationship norm is most applicable to a specific interaction, interactions in which no relationship norm whatsoever is used, seem nonexistent. People will infer the most applicable relationship norms based on information available. This implies that attributional thoughts related to relationship norms will be aroused by an interaction itself, and potentially overrule the influence of any unobtrusively activated relationship norms (Gilbert \& Hixon, 1991). Previous research showed that impairing the cognitive capacity of respondents during the presentation of the target stimuli significantly reduced their ability to engage in attributional thoughts regarding these stimuli (Gilbert, Pelham, \& Krull, 1988). Thus, deliberate attributional thoughts regarding relationship norms applicable to a target interaction itself, are less likely to occur and subsequently to interfere with the unobtrusively primed relationship norms when participants have a reduced cognitive capacity while they are exposed to the target interaction (Bargh, 1999). We therefore expected the strongest effects of primed relationship norms on judgments of a target interaction when the capacity of the respondents is impaired, in line with the 
expected automatic nature of this process. Note in this respect that in the hassle of everyday life, reduced cognitive capacity is the norm rather than the exception.

To summarize, financially stimulated word-of-mouth referrals contain aspects of both equality matching (the common relationship for referrals) and market pricing (introduced by the financial reward for the advice). When an MP relationship norm is activated, it is relatively more normal and accepted to advise products with the goal of earning money, than within an EM relationship. This would result in more sincere agent judgments when an MP relationship norm is activated than when an EM norm is activated. In line with Campbell and Kirmani (2000), we specifically looked at the sincerity judgments of the agent. Sincerity is a key trait in judging others (e.g., Anderson, 1968), especially if there are multiple motives that might underlie their behavior (in this case both helping a friend and making money; (Fein, 1996; Marchand \& Vonk, 2005; see also Darke \& Ritchie, 2007).

We expected this effect of relationship norms to occur on an automatic level (after unobtrusive activation), and to be stronger when the cognitive capacity of the agent is impaired while processing information. Impaired cognitive capacity limits the ability of the perceiver to infer relationship norms from the target scenario itself. As a result, he or she will rely relatively more on the norm that is activated unobtrusively. Hypothesis 1: When EM is unobtrusively activated as relationship frame, an interaction partner with underlying financial motives will be perceived as less sincere than when an MP frame is activated. This effect will be more pronounced when the cognitive capacity of the respondent is impaired than when the capacity is not impaired. 
With regard to the intention to comply with the referral, we expected a different pattern of results. Resistance is one of the central aspects of the customer-seller (i.e. MP) relationship (Kirmani \& Campbell, 2004; Williams, Fitzsimons, \& Block, 2004), and subsequently more appropriate and easily applied in customer-seller relationships in comparison to other types of relationships. Therefore, we expected lower compliance intentions with the referral when MP relationship norms are activated than when EM relationship norms are activated. Again, we expected the strongest effects when the capacity of the respondents is impaired.

Hypothesis 2: When EM is unobtrusively activated as relationship frame, an interaction partner with underlying financial motives will lead to higher compliance tendencies than when an MP frame is activated. This effect will be more profound when the cognitive capacity of the respondent is impaired than when the capacity is not impaired.

The impact of disclosures

Finding evidence for the above stated hypotheses would support our reasoning that rewarded WOM recommendations contain aspects of both EM and MP relationship norms, and that both norms have a unique and highly automatic impact on evaluations of rewarded recommendations. In daily live, people might quite easily apply an EM relationship frame to a rewarded recommendation, since non-rewarded recommendations also occur within EM relationship frames. This implies that, besides gaining insights in the impact of MP versus EM relationship norms, it is relevant to understand the impact of rewards on recommendation evaluations within EM relationship frames. As we discussed above, disclosing or not disclosing the financial reward is a topic of continuous debate 
within buzz marketing, and the precise impact of disclosing the financial motive remains unclear. Besides gaining empirical insight in the impact of disclosing a financial reward within a WOM context, investigating disclosures would also show whether the impact of activated MP norms on evaluations is unique, or comparable to disclosure effects.

It is not clear, however, how a disclosure would affect consumers' reponses to rewarded referrals within EM settings. On the one hand, in line with practitioners' objections, disclosure emphasizes that the referring customer is (at least partly) motivated by a financial gain, which may result in less favorable agent evaluations. The disclosure might highlight that the referring agent is motivated by money, which is not the appreciated within EM relationships and could result in lower sincerity judgments. This is line with research within the persuasion knowledge area, that argues that persuasion agents are judged less favorably when ulterior motives are more salient and people have cognitive capacity available to process these motives (Campbell \& Kirmani, 2000; see also Kirmani \& Zhu, 2007; Williams et al., 2004).

On the other hand, disclosure may mitigate consumers' unfavorable response to financial rewards in EM settings. Disclosing financial motives may create the impression that "buzzing" customers are honest and open about their motives. This may be appreciated by receiving consumers, and result in more favorable evaluations than when the reward is not disclosed (Forehand \& Grier, 2003). Since manipulative or financial motives are seldomly the main driver of word-of-mouth recommendations (e.g., Wirtz \& Chew, 2002), we expect a disclosure of a financial reward to have a positive, rather than a negative effect on the sincerity evaluations of the recommending agent. People are unlikely to infer that a word-of-mouth recommendation occurs mainly out of self-interest 
rather than out of product enthusiasm, especially when someone discloses this reward. No disclosure leaves room for suspicion and questioning the real intentions, and would therefore result in lower sincerity evaluations than a disclosure. In line with Johar and Simmons (2000), we expect the impact of disclosures on evaluations to be bigger when respondents have full cognitive capacity available. Since respondents are able to engage in more extensive processing of the scenario when their capacity is not impaired, they will be able to reflect on the (lack of) disclosure, and adjust their judgment accordingly. Hypothesis 3: Within an EM relationship norm, disclosing a sales motive will lead to more sincere judgments of interaction partners than not disclosing this motive, but only when the capacity of the respondents is not impaired.

Contrary to the impact of MP relationship norms, in which non-compliance is more common and acceptable than within EM relationship norms, we do not expect to find any effects of disclosure on compliance intentions (see also Campbell and Kirmani, 2000). Disclosing or not disclosing a financial motive is expected to influence agent evaluations rather than intentions to try the product, and thus comply with the recommendation.

\section{Pilot Study}

To establish whether stimulated word-of-mouth referral is more appropriate within MP relationships than within EM relationships, we conducted a pilot study $(N=$ 116). Students read a scenario in which they had to imagine having lunch in the college cafeteria, and then being approached by Frank. According to the scenarion, they had not met Frank before, but he is either introduced as working for a magazine (MP), or as a fellow student (EM). In this scenario, Frank speaks enthusiastically about a magazine and 
gives the student a coupon for a trial subscription at a reduced rate. The student ('you') later notices that Frank receives $10 \%$ of the subscription price for every new subscriber. We asked respondents to judge whether the behavior of Frank was inappropriate and unacceptable $(\alpha=.87$; both 7 -point scales, $1=$ totally disagree; $7=$ totally agree $)$. Franks behavior was indeed judged as more inappropriate when he was a fellow student $(M=$ $3.77 ; S D=1.48)$ than when he worked for the magazine $(M=3.17 ; S D=1.40), t(114)=$ $2.23, p<.05$. These results confirm that a referral instigated by a financial reward is more appropriate within an MP relationship than within an EM relationship.

\section{Study 1}

In Study 1, we tested Hypothesis 1 and 2, and aimed to show that the unobtrusive activation of a relationship frame (either MP or EM) has an influence on the perception and judgment of the behavior of the referral agent and on the intention to comply with his referral.

Method

Participants. Participants were 103 students (26 male, 77 female) who participated for course credit or $€ 5$.

Procedure. The experiment had a 2 (Relationship Norm Activation: Market Pricing versus Equality Matching) x 2 (Cognitive Capacity: Impaired versus Full) between subjects design.

Participants sat behind a computer screen, in individual cubicles. They were told that the experiment consisted of several unrelated parts. The first part (the relationship activation manipulation) was introduced as research on word recognition time. This was a word search paradigm adapted from Van den Berg, Manstead, van der Pligt, and 
Wigboldus (2006). Participants were instructed to search for 15 hidden words in a $10 \times 9$ letter matrix. Next to five filler words, we used 10 words to manipulate relationship norms. In the MP relationship condition, these words were related to the marketplace (e.g., price, store, purchase). In the EM condition, these words were related to students (e.g., lecturer, desk, pencil). We used 'student words' because these would lead student participants to think of people with whom they have EM relationships in daily life (i.e. fellow students). A pretest $(N=112)$ confirmed that these words were categorized as intended. We gave respondents the descriptions of both relationship types and asked them to classify the words to the extent that they fit with one of the relationship types $(1=$ definitely EM; 9 = definitely MP); The MP words were categorized as more MP $(M=$ $7.44 ; S D=1.36)$ than the EM words $(M=4.92 ; S D=1.20), t(111)=19.09, p<.01$.

After completing the word-search task, the 'second' task was introduced as a task on impression formation and contained the target scenario. Before reading the scenario, we manipulated the amount of available cognitive capacity. Respondents got the instruction to remember either eight (impaired capacity) or one digit (full capacity) until asked to report them (Krull, 1993).

While keeping these digits in mind, they received the following scenario to read: "Imagine being allocated for an assignment for your major to Paul, a fellow student who you don't know. For a meeting, he brought a new magazine with him, which is focussed on your major. An article from this magazine helps you with accomplishing the assignment. Paul is very enthusiastic about the journal. After your meeting, he gives you his copy, so that you can have a closer look at it. When you are at home, you notice the following coupon:” 
After participants pressed enter, a 'member-get-member' coupon appeared on the screen. This coupon stated the subscription rate, and that the current member would receive $€ 10$ of gift vouchers for every new member; the latter part was already filled in by Paul with his name and subscriber's number.

After reading the scenario, we measured the perceived sincerity of Paul with the following items; Paul is: "sincere", "trustworthy", and "reliable". To examine whether the primary effect of different relationship norms is indeed on perceived sincerity and not on other personality judgments, we also measured liking with the items "Paul is nice" and "Paul is sympathetic". Compliance intentions towards the offer were measured with the following items: "I consider becoming a subscriber to this journal", "I am curious about the journal", "I consider filling in the coupon" and "I am interested in the journal". All items were measured on 7 -point scales $(1=$ totally disagree, $7=$ totally agree $)$. After responding to these scales, participants were asked to write down the digits they were remembering. Subsequently, we asked participants whether they felt that they could pay less attention to the scenario due to the remembrance task ( 7 -point scale, $1=$ not at all, 7 $=$ very much). We used a funneled debriefing questionnaire protocol (Bargh \& Chartrand, 2000) to probe for suspicion regarding the goal of the study and the connection between the different parts. Participants were debriefed when finished. Results

Manipulation checks. We checked recall of the digits, and removed 10 participants from further analysis who did not remember four or more digits correctly (following Gilbert \& Hixon, 1991). Participants in the full cognitive capacity condition felt that their attention was less impaired when reading the scenario $(M=1.75, S D=$ 
1.34) then participants in the impaired capacity condition $(M=3.93, S D=1.80), t(91)=$ $6.66, p<.001$. The debriefing questionnaire showed no signs of suspicion.

Dependent variables. Evidence for the discriminant validity of our measures was obtained in a series of confirmatory factor analyses (CFAs). These CFAs showed a satisfactory fit for a three-factor model, in which the items are divided into "compliance" (four items), "sincerity" (three items), and "liking" (two items; $\chi^{2}(24)=85.46, p<.05$, $\mathrm{CFI}=.86, \mathrm{GFI}=.82$ ). This model outperforms both a two-dimensional (in which liking and sincerity are combined; $\left.\chi^{2}(26)=104.87, p<.05, \mathrm{CFI}=.83, \mathrm{GFI}=.78\right)$ and a onedimensional model, in which all items are combined into one factor $\left(\chi^{2}(27)=236.21, p\right.$ $<.05, \mathrm{CFI}=.54, \mathrm{GFI}=.63)$. A pseudo $\chi^{2}$ test confirmed that the better fit of the three dimensional model is significant, both compared with the two-factor model $\left(\Delta \chi^{2}(2)=\right.$ $19.41, p<.001)$ and with the one-factor model $\left(\Delta \chi^{2}(3)=150.75, p<.001\right)$. Further support for discriminant validity is provided by the fact that the average variance extracted for each construct $(\mathrm{AVE}$ liking $=.68$; AVE sincerity $=.57$; AVE compliance $=$ .49) was always higher than the squared correlation between the focal construct and the two remaining constructs $\left(\varphi^{2}\right.$ liking-sincerity $=.53 ; \varphi^{2}$ liking-compliance $=.04 ; \varphi^{2}$ compliance-sincerity $=.06)$.

An ANOVA showed a significant two-way interaction between relationship and cognitive capacity for perceived sincerity $(\alpha=.75), F(1,89)=5.10, p<.03$ (see Figure 1). When their cognitive capacity was impaired, participants judged the referring customer as more sincere when MP was activated $(M=4.67)$, than when EM was activated $(M=4.03), F(1,89)=4.05, p<.05$. This difference disappeared within the high available capacity condition, $F(1,89)=1.16, p>.10$ (see Table 1 for means). 
As expected, the compliance intention measure $(\alpha=.84)$ showed a significant two-way interaction, $F(1,89)=5.06, p<.03$ with a pattern of means that was different from the one observed for perceived sincerity (see Figure 2). Testing simple main effects revealed that the activated relationship norms again only influenced judgments under impaired capacity, $F(1,89)=6.48, p=.01$. When the participants had full available cognitive capacity there were no significant differences, $F<1$ (see Table 2 for means). In line with Hypothesis 2, when capacity was impaired, compliance intention was lower when MP norms were activated $(M=3.61)$ than when EM norms were activated $(M=$ 4.65). The liking judgment $(\alpha=.78)$ did not reveal any significant effects, $F$ 's $<1$.

We examined the relationship between perceived sincerity and compliance. One could argue, for example, that a lower degree in perceived sincerity should also result in lower compliance intentions, and that the compliance intentions (after correcting for the impact of sincerity) should reflect even greater differences due to the norm activation. However, the bivariate correlation between compliance intentions and perceived sincerity was small and insignificant $(r=.10, p=.34)$. When we included sincerity as a covariate in the model with compliance as the dependent variable, then this covariate approached significance, $F(1,88)=3.26, p=.07$. The interaction effect of relationship norm and cognitive capacity became somewhat stronger, but this change was not significant (Sobel test $Z=1.41, p>.10)$. This indicated that the compliance effect was not mediated by perceived sincerity.

\section{Discussion}

The results of Study 1 support Hypotheses 1 and 2. When an MP relationship norm was activated, participants perceived the referral agent as more sincere, but were 
less likely to comply with his offer. Interestingly, we only found these effects when the cognitive capacity of participants was impaired. This provides compelling evidence for our idea that relationship norms exert influence on perceptions and judgments of interaction partners in an efficient way. When people are able to engage in more extensive thinking about the target interaction, the impact of previously activated constructs is limited, but when they are unable to spend cognitive resources to a target interaction, previously activated relationship norms influence the interpretation of the target interaction in such a way that this interaction is evaluated along the lines of the activated relationship norms.

We argued that, in the current context, norm violations will affect sincerity judgments, rather than liking judgments. In line with this reasoning, we found effects on the sincerity measure, but not on the liking scale. This goes against an alternative explanation, in which the effects are due to a difference in fluency between prime and behavior $^{1}$. That is, advising something in order to gain a reward is more congruent with MP than with EM norms, which subsequently could have lead to more fluent processing. However, as Reber and colleagues (Reber, Schwarz, \& Winkielman, 2004; Reber, Winkielman, \& Schwarz, 1998) indicate, an increase in processing fluency leads to an increase in liking in the first place, because processing fluency is an indication of progress towards successful recognition of the stimulus, which results in more (general) positive feelings (such as an increase in liking). If priming respondents with MP versus EM had caused a difference in congruency (and subsequently in processing fluency), we should have found differences on the general liking judgments, and not so much on a more specific judgment, such as sincerity. The current results are therefore more in line 
with the hypothesized norm violation account, which predicts differences in sincerity judgments and not necessarily in liking judgments.

Another alternative explanation ${ }^{2}$ of our results is that, within an MP frame, selling behavior is more expected, so that the MP context itself serves as a disclosure of the underlying (selling) motive for the referral. In that case it is not the selling itself that is inappropriate within EM norms, but the unexpectedness of the selling behavior, i.e., the lack of disclosure of the underlying (selling) motive. In Study 2, we examined the impact of disclosing the reward within an EM relationship frame. If a lack of disclosure forms the underlying explanation for our effects, we should find an effect of disclosure versus no disclosure that is comparable to the effect of MP versus EM in the first study. However, in line with Hypothesis 3, we expect disclosures to have a positive impact on sincerity evaluations, but only when the respondent has the capacity available to incorporate the disclosure in his evaluations.

Study 2

Method.

Participants. 147 students (70 male and 77 female) participated in this study in exchange for a small gift or course credit.

Procedure. The experiment had a 2 (Disclosure: Disclosure versus No Disclosure) x 2 (Cognitive Capacity: Impaired versus Not Impaired) between subjects design. The procedure of this study resembled the procedure of Study 1 to a large extent. We primed all respondents with an EM frame, similar to the one used in Study 1. The disclosure was manipulated by adding (or not) a disclosure statement to the original scenario (see below, disclosure in brackets): 
"Imagine being allocated for an assignment for your major to Paul, a fellow student who you don't know. For a meeting, he brought a new magazine with him, which is focussed on your major. An article from this magazine helps you with accomplishing the assignment. Paul is very enthusiastic about the journal. After your meeting, he gives you his copy, so that you can have a closer look at it. (He tells you that he will receive 10 euros when you subscribe to the magazine.) When you are at home, you notice the following coupon:”

The dependent measures (sincerity, liking and compliance) were equal to Study 1. As manipulation checks, we asked respondents whether they noticed that Paul received a financial reward for a new customer, and whether Paul had told them about the reward. Results

Manipulation checks. We removed 28 respondents who failed to notice that Paul would receive money for a new subscriber or who incorrectly answered the disclosure manipulation check (i.e., did not notice that Paul revealed that he would receive money in the disclosure condition or the opposite in the no disclosure condition) $)^{3}$.

Dependent variables. There was a significant main effect of disclosure on sincerity, $F(1,115)=13.78, p<.001$; Paul was judged more sincere in the condition with disclosure $(M=4.72 ; \mathrm{SD}=1.02)$ than without disclosure $(M=3.95 ; \mathrm{SD}=1.02)$. This main effect was qualified by a significant interaction effect between the capacity manipulation and the disclosure manipulation, $F(1,115)=4.25, p<.05$ (see Figure 3). With full cognitive capacity available, respondents judged Paul as more sincere in the disclosure condition $(M=4.83)$ than in the no disclosure condition $(M=3.73), F(1,115)$ $=20.93, p<.001$. When capacity was impaired, there was no difference between 
disclosure and no disclosure, $F(1,115)=1.00$, ns (see Table 3 for means). In line with Study 1, the difference between full and impaired cognitive capacity in the no disclosure condition, was not significant.

There were no significant main or interaction effects of capacity and disclosure on compliance intentions, neither on liking judgments, all $p$ 's $>.15$. This is not unexpected and indicates that the agent, and not (the supplier of) the product, is fully responsible for disclosing or not disclosing these kinds of motives, and that this disclosure does not influence compliance intentions.

\section{Discussion}

The results of Study 2 provide insight into the impact of disclosing or not disclosing a financial reward within financially stimulated word-of-mouth recommendations. In line with Hypothesis 3, they show the positive but limited effects of disclosure; the disclosure only had an impact on respondents with ample cognitive capacity. Only under these conditions, a disclosure led to more sincere judgments than no disclosure. This indicates that disclosing a financial motive is appreciated by consumers, but that cognitive effort is required to process such disclosures.

Furthermore, the current results also confirm that the differences found between MP and EM within the low capacity condition in Study 1 are not driven by a difference in disclosure of the selling motive, since disclosure requires capacity to influence sincerity judgments, whereas MP norms influence judgments under conditions of low available cognitive capacity. 


\section{General Discussion}

Our hypotheses were confirmed in a set of three studies. A pilot study confirmed that a financially stimulated word-of-mouth referral is judged as more appropriate when it is framed as an MP interaction than when framed as an EM interaction. This supports the claim that rewarded referrals fit better with MP relationship norms than with EM relationship norms. In the first study, we examined the automatic and efficient nature of these relationship norms, their impact on the perceptions and judgments of our interaction partners and the intention to comply with their recommendations. In the second study, we examined the impact of disclosing or not disclosing the financial motives on these evaluations. We showed that, under conditions of limited available cognitive capacity, activation of different relationship norms led to evaluating the interaction partner in line with these norms, resulting in higher sincerity judgments and lower compliance intentions when an MP norm was activated (in which both selling and rejecting sales offers are common practice) than when an EM norm was activated. The second study showed that disclosing the motive led to more favorable evaluations of the interaction partner, but only when the respondent had full cognitive capacity available. These studies contribute to the literature on relationship norms and on norms in general, and on wordof-mouth referrals. We will discuss these contributions below.

\section{Relationship Norms}

First, we extend the literature on the automatic impact of environmental norms on behaviors by showing the automatic impact of relationship norms on interpersonal interactions, perceptions and judgments. Where previous research (e.g., Aarts \& Dijksterhuis, 2003) mainly focused on the impact of activated situational norms on how 
people behave themselves, we showed the impact of relationship norms on the judgment and evaluation of our interaction partners.

Second, we contribute to the research on relationship norms by showing their highly automatic nature. We showed that norms regarding the behaviors that are legitimate within a specific relationship influence our perceptions of (seemingly unrelated) interactions and the way we judge our interaction partners after an unobtrusive activation procedure. Thereby, we contribute to previous research on relationship norms (e.g., McGraw and colleagues, 2003, 2005) by providing insight in the process of how relationship norms exactly influence evaluations. By activating relationship norms in an unobtrusive way (separate from the target scenario) and finding effects under conditions of impaired cognitive capacity, we can also rule out alternative explanations that have been raised for previous studies on relationship norms (Johar, 2005; Kahn, 2005). Note that we have limited our research to ambiguous situations, where it is not immediately obvious which relationship norm is most applicable to the situation. If a situation evokes an obvious and strong relationship norm, subtle cues are not likely to impact judgments of interaction partners. However, there are plenty of situations in daily life in which the relationship is not immediately apparent. For example, when you are inside a clothing store and someone says that a sweater looks good on you, your first inference is probably "salesperson" (MP). If you see, however, that the person wears a coat, you may conclude that he or she is also a customer who just walked into the store, which activates a different set of norms and leads to a different response.

Finding the strongest effects of the activated norms under conditions of limited cognitive capacity is not a limitation of the current studies. In daily life, consumers 
almost never pay full attention to their interactions, which makes it very plausible that relationship norms that get activated by subtle (environmental) cues influence our perceptions of our interaction partners. In fact, our impaired cognitive capacity condition may be closer to real life (consumer related) situations and decisions than the high capacity condition (cf. Dijksterhuis, Smith, van Baaren, \& Wigboldus, 2005). Word-of-mouth referrals

We contribute to the literature on financially stimulated word-of-mouth referrals. Ryu and Feick (2007) showed that stimulating referrals with financial rewards leads to higher referral likelihood, but they were silent about the effects of stimulating referrals on the receiving consumers. Our research demonstrates that the effectiveness of referrals can be influenced by manipulating the relationship norm that is salient during the interaction. Compared to MP norms, the activation of EM norms led to an increase in "sales" (i.e., the tendency to comply with the referral), and a decrease in perceived sincerity of the referring customer. This implies that there might be a difference between the long term and the short term effectiveness of word-of-mouth marketing. On the short term, framing referrals as part of an EM relationship increases compliance. This does, however, lead to lower levels of perceived sincerity, which might have negative effects on compliance intentions in the long run. From a long run perspective, introducing MP norms in these interactions might be more recommendable. Furthermore, the results of our second study show that, within EM relationship norms, disclosing these sales motives can have positive effects on the evaluations of the agent, but only when targets have ample cognitive capacity available. 
These results are remarkable, considering the general assumption that referral campaigns are effective because of the absence of marketing interests (cf. Creamer, 2005; Silverman, 2001). We do not want to refute that statement, but aim to show the boundaries of this common belief. Referral campaigns are quite commonly instigated by rewards (i.e., money, a present, or some sort of discount, cf. Godin, 2002; Ryu \& Feick, 2007), and the target of the referral campaign can become aware of these ulterior motives. In fact, Creamer (2005) notes that it might even be legally required to disclose the financial reward. Objections to requiring a disclosure from a company point of view do not seem to hold in light of our research findings. On the contrary, in these situations in which it is likely that the target of the referral will find out about the financial motives sooner or later (which is the case for many of these campaigns), disclosing can lead to more positive agent evaluations than not disclosing. At the same time, the positive impact of disclosures is only limited, regarding the need for cognitive capacity in order to be able to incorporate the disclosure in final evaluations, and the lack of effect of disclosures on compliance intentions. Our research does suggest that introducing sales related aspects in a rewarded recommendation interaction (either in a subtle way by activating relationship norms, or in a more blatant way by disclosing the reward) can have positive effects on the evaluations of the recommending agent.

Compliance intentions were affected by relationship norm activation, but not by disclosures. This is in line with our expectations. Within EM relationships, people are not used to deny advice or ignore recommendations, whereas within MP relationships, this is common practice, and people thus more easily comply to recommendations from EM interaction partners than from MP interaction partners. Disclosing or not disclosing 
underlying motives is a decision which is up to the referring customer, and will therefore mainly affect evaluations of the referring customer, rather than intentions of the referral target to comply with the recommendation. Although we only investigated the impact of disclosures within an EM relationship norm, we think that disclosures in general will in the first place become apparent in person evaluations rather than in compliance intentions, irrespective of the relationship norm guiding that interaction. However, future research should be done in order to confirm this expectation.

\section{Limitations and future research}

Our research differs in important aspects from the persuasion knowledge literature that focused on agent evaluations (Campbell \& Kirmani, 2000; Campbell \& Kirmani, forthcoming; Main, Dahl, \& Darke, 2007). This previous research showed that flattery within a sales context more easily leads to inferences of ulterior motives, which results in less favorable (or sincere) agent evaluations. We did not look at flattery, but examined the influence of different relationship norms on how people evaluate behavior that is driven by an ulterior motive. Furthermore, we examined the impact of the relationship norms within a word-of-mouth setting, and one of the important factors that differentiates a word-of-mouth context from common sales contexts, is the relationship between the agent and the target.

The current research focused on the difference between MP and EM frames, because these two frames seem most relevant in the context of word-of-mouth marketing: referrals usually occur within EM relationships, while financial rewards for referrals introduce an MP component. However, it may be worthwhile to examine also the roles of communal sharing (CS) and authority ranking (AR) relationship types (Fiske, 1992) in a 
persuasion context. CS frames could for example apply to word of mouth among close friends or family, while AR frames could be relevant in the workplace, or situations such as doctors advising patients or teachers advising students. Within CS relationships, both moral considerations (i.e., "selling" something to someone with whom you have a CS relationship is in general very norm violating) and the tendency to comply might be augmented in comparison to EM relations. With regard to AR relations, a (financially stimulated) referral from an authority (for example your doctor or your boss) might increase compliance because of the tendency to obey authorities, whereas sincerity might be less crucial in these relationships than in EM relationships.

An interesting angle for future research might be to look at the type of reward provided by the firm, and in this way, looking at the differential relationship types possible between the company and the referring agent (Heyman \& Ariely, 2004). By providing a financial reward, this relationship is typical MP (or a 'monetary market'; Heyman \& Ariely), whereas, for example, providing a small gift or a free sample might be more in line with EM (or a 'social market') and subsequently exert a differential impact on the way this agent is perceived by the target, and the compliance intention.

To conclude, we demonstrated that the activation of different relationship norms can facilitate or hinder persuasion, and influences persuasion agent evaluations, depending on the match between the relationship and the behavior. Our findings thereby contribute to our understanding of consumers' responses to persuasion attempts, and the processes underlying these responses 


\section{References}

Aarts, H., \& Dijksterhuis, A. (2003). The silence of the library: Environment, situational norm, and social behavior. Journal of Personality and Social Psychology, 84, 18-28.

Aarts, H., Dijksterhuis, A., \& Custers, R. (2003). Automatic normative behavior in environments: The moderating role of conformity in activating situational norms. Social Cognition, 21, 447-464.

Aggarwal, P. (2004). The effects of brand relationship norms on consumer attitudes and behavior. Journal of Consumer Research, 31, 87-101.

Ahluwalia, R., \& Burnkant, R. E. (2004). Answering questions about questions: A persuasion knowledge perspective for understanding the effects of rhetorical questions. Journal of Consumer Research, 31, 26-42.

Anderson, N. H. (1968). Likeableness ratings of 555 personality-trait words. Journal of Personality and Social Psychology, 9, 272-279.

Bargh, J. A. (1994). The four horsemen of automaticity: Awareness, intention, efficiency, and control in social cognition. In R. S. Wyer \& T. K. Srull (Eds.), Handbook of social cognition. (Vol. 1, pp. 1-40). Hillsdale, NJ: Lawrence Erlbaum Associates.

Bargh, J. A. (1999). The cognitive monster: The case against the controllability of automatic stereotype effects. In S. Chaiken \& Y. Trope (Eds.), Dual-Process Theories in Social Psychology (pp. 361-382). New York: Guilford.

Bargh, J. A., \& Chartrand, T. L. (2000). The mind in the middle: A practical guide to priming and automaticity research. In H. Reis \& C. M. Judd (Eds.), Handbook of Research Methods in Social and Personality Psychology (pp. 253-285). New York: Cambridge University Press. 
Campbell, M. C., \& Kirmani, A. (2000). Consumers' use of persuasion knowledge: The effects of accessibility and cognitive capacity on perceptions of an influence agent. Journal of Consumer Research, 27, 69-83.

Campbell, M. C., \& Kirmani, A. (2008). I know what you're doing and why you're doing it: The use of persuasion knowledge in consumer research. In C. P. Haugtvedt, P. M. Herr \& F. R. Kardes (Eds.), Handbook of Consumer Psychology (pp. 549-573). Psychology Press.

Cialdini, R. B. (2003). Crafting normative messages to protect the environment. Current Directions in Psychological Science, 12, 105-109.

Cialdini, R. B. (2007). Descriptive social norms as underappreciated sources of social control. Psychometrika, 72, 263-268.

Creamer, M. (2005). Is buzz marketing illegal? Advertising Age, 76, 6.

Darke, P. R., \& Ritchie, R. J. B. (2007). The defensive consumer: Advertising deception, defensive processing, and distrust. Journal of Marketing Research, 44, 114-127.

DeCarlo, T. E. (2005). The effects of sales message and suspicion of ulterior motives on salesperson evaluation. Journal of Consumer Psychology, 15, 238-249.

Dijksterhuis, A., Smith, P. K., van Baaren, R. B., \& Wigboldus, D. H. J. (2005). The unconscious consumer: Effects of environment on consumer behavior. Journal of Consumer Psychology, 15, 193-202.

Fein, S. (1996). Effects of suspicion on attributional thinking and the correspondence bias. Journal of Personality and Social Psychology, 70, 1164-1184.

Fiske, A. P. (1992). The four elementary forms of sociality: Framework for a unified theory of social relations. Psychological Review, 99, 689-723. 
Folkes, V. S. (2002). Is consumer behavior different? Advances in Consumer Research, 29, 1-4.

Forehand, M. R., \& Grier, S. (2003). When is honesty the best policy? The effect of stated company intent on consumer skepticism. Journal of Consumer Psychology, 13, 349-356.

Friestad, M., \& Wright, P. (1994). The persuasion knowledge model: How people cope with persuasion knowledge. Journal of Consumer Research, 21, 1-31.

Gilbert, D. T., \& Hixon, J. G. (1991). The trouble of thinking: Activation and application of stereotypic beliefs. Journal of Personality and Social Psychology, 60, 509-517.

Gilbert, D. T., Pelham, B. W., \& Krull, D. S. (1988). On cognitive busyness: When person perceivers meet persons perceived. Journal of Personality and Social Psychology, 54, 733-740.

Godes, D., Mayzlin, D., Chen, Y. B., Das, S., Dellarocas, C., Pfeiffer, B., et al. (2005). The firm's management of social interactions. Marketing Letters, 16), 415-428.

Godin, S. (2002). Unleashing the ideavirus. London: Simon \& Schuster.

Grayson, K. (2007). Friendship versus business in marketing relationships. Journal of Marketing, 71, 121-139.

Heyman, J., \& Ariely, D. (2004). Effort for payment. A tale of two markets. Psychological Science, 15, 787-793.

Johar, G. V. (2005). The price of friendship: When, why, and how relational norms guide social exchange behavior. Journal of Consumer Psychology, 15, 22-27.

Johar, G. V., \& Simmons, C. J. (2000). The use of concurrent disclosures to correct invalid inferences. Journal of Consumer Research, 26, 307-322. 
Kahn, B. E. (2005). The power and limitations of social relational framing for understanding consumer decision processes. Journal of Consumer Psychology, 15, 28-34.

Kirmani, A., \& Campbell, M. C. (2004). Goal seeker and persuasion sentry: How consumer targets respond to interpersonal marketing persuasion. Journal of Consumer Research, 31, 573-582.

Kirmani, A., \& Zhu, R. (2007). Vigilant against manipulation: The effect of regulatory focus on the use of persuasion knowledge. Journal of Marketing Research, 44, $688-701$.

Krull, D. S. (1993). Does the grist change the mill? The effect of perceiver's inferential goal on the process of social inference. Personality and Social Psychology Bulletin, $19,340-348$.

Main, K. J., Dahl, D. W., \& Darke, P. R. (2007). Deliberative and automatic bases of suspicion: Empirical evidence of the sinister attribution error. Journal of Consumer Psychology, 59-69.

Marchand, M. A. G., \& Vonk, R. (2005). The process of becoming suspicious of ulterior motives. Social Cognition, 23, 242-256.

McGraw, A. P., \& Tetlock, P. E. (2005). Taboo trade-offs, relational framing, and the acceptability of exchanges. Journal of Consumer Psychology, 15, 2-15.

McGraw, A. P., Tetlock, P. E., \& Kristel, O. V. (2003). The limits of fungibility:

Relational schemata and the value of things. Journal of Consumer Research, 30, 219229. 
Petty, R. E., \& Wegener, D. T. (1998). Attitude change: Multiple roles for persuasion variables. In D. T. Gilbert, S. Fiske \& G. Lindzey (Eds.), Handbook of Social Psychology. (4th ed., Vol. 1, pp. 323-390). New York: McGraw-Hill.

Priester, J. R., \& Petty, R. E. (2003). The influence of spokesperson trustworthiness on message elaboration, attitude strength, and advertising effectiveness. Journal of Consumer Psychology, 13, 408-421.

Reber, R., Schwarz, N., \& Winkielman, P. (2004). Processing fluency and aesthetic pleasure: Is beauty in the perceiver's processing experience? Personality and Social Psychology Review, 8, 364-382.

Reber, R., Winkielman, P., \& Schwarz, N. (1998). Effects of perceptual fluency on affective judgments. Psychological Science, 9, 45-48.

Reinhard, M. A., Messner, M., \& Sporer, S. L. (2006). Explicit persuasive intent and its impact on success at persuasion - The determining roles of attractiveness and likeableness. Journal of Consumer Psychology, 16(3), 249-259.

Rosen, E. (2000). The anatomy of Buzz. London: Simon \& Schuster.

Ryu, G., \& Feick, L. (2007). A penny for your thoughts: Referral reward programs and referral likelihood. Journal of Marketing, 71, 84-94.

Shin, A. (2006, December 12). FTC moves to unmask word-of-mouth marketing. Washington Post, p. D01.

Silverman, G. (2001). The power of word of mouth. Direct Marketing, 64, 47-52.

Thaler, R. H. (1985). Mental accounting and consumer choice. Marketing Science, 4, $199-214$ 
Van den Berg, H., Manstead, A. S. R., van der Pligt, J., \& Wigboldus, D. H. J. (2006). The impact of affective and cognitive focus on attitude formation. Journal of Experimental Social Psychology, 42, 373-379.

Williams, P., Fitzsimons, G., \& Block, L. G. (2004). When consumers do not recognize "benign" intention questions as persuasion attempts. Journal of Consumer Research, $31,540-550$.

Wirtz, J., \& Chew, P. (2002). The effects of incentives, deal proneness, satisfaction and tie strength on word-of-mouth behavior. International Journal of Service Industry Management, 13, 141-162. 


\section{Footnotes}

1,2 We would like to thank the anonymous reviewers for these valuable suggestions.

3 We are aware of the fact that this is a relatively large number. In line with our reasoning (and see also Johar \& Simmons, 2000) that incorporating a disclosure in a judgment would require cognitive effort, most (23) of these respondents were in the impaired capacity condition. However, we think it is of crucial importance for properly testing our hypothesis that the respondents have a correct recall of the disclosure. If we do look at the complete sample, the focal interaction effect for sincerity remains significant $F(1,88)=5.43, p=.02$, and the associated pattern of means is the same as the one reported above. 
Table 1

Perceived Sincerity as Function of Relationship and Cognitive Capacity (Means and SD's; Study 1)

\begin{tabular}{llll}
\hline & \multicolumn{2}{c}{ Impaired capacity } & Full capacity \\
\cline { 2 - 4 } MP activation & Mean & $4.67^{\mathrm{a}}$ & $4.05^{\mathrm{b}}$ \\
& SD & 0.98 & 0.92 \\
EM activation & Mean & $4.03^{\mathrm{b}}$ & $4.33^{\mathrm{b}}$ \\
& SD & 0.85 & 1.10 \\
\hline
\end{tabular}

Note. Cells with a different superscript differ significantly from each other $(p<.05)$.

Table 2

Compliance as Function of Relationship and Cognitive Capacity (Means and SD's; Study

1)

\begin{tabular}{|c|c|c|c|}
\hline & & $\operatorname{Imp}$ & Full capacity \\
\hline \multirow[t]{2}{*}{ MP activation } & Mean & $3.61^{\mathrm{a}}$ & $4.64^{b}$ \\
\hline & SD & 1.72 & 1.12 \\
\hline \multirow[t]{2}{*}{ EM activation } & Mean & $4.65^{b}$ & $4.38^{b}$ \\
\hline & SD & 1.12 & 1.31 \\
\hline
\end{tabular}

Note. Cells with a different superscript differ significantly from each other $(p<.05)$. 
Table 3

Perceived Sincerity as Function of Disclosure and Cognitive Capacity (Means and SD's; Study 2)

\begin{tabular}{|c|c|c|c|}
\hline & & Impa & Full capacity \\
\hline \multirow[t]{2}{*}{ Disclosure } & Mean & $4.53^{\mathrm{a}}$ & $4.83^{\mathrm{a}}$ \\
\hline & $\mathrm{SD}$ & 1.16 & 0.94 \\
\hline \multirow[t]{2}{*}{ No disclosure } & Mean & $4.21^{\mathrm{a}, \mathrm{b}}$ & $3.73^{b}$ \\
\hline & SD & 0.98 & 1.01 \\
\hline
\end{tabular}

Note. Cells with a different superscript differ significantly from each other $(p<.05)$.

Figure 1

Perceived Sincerity as Function of Relationship and Cognitive Capacity, Study 1

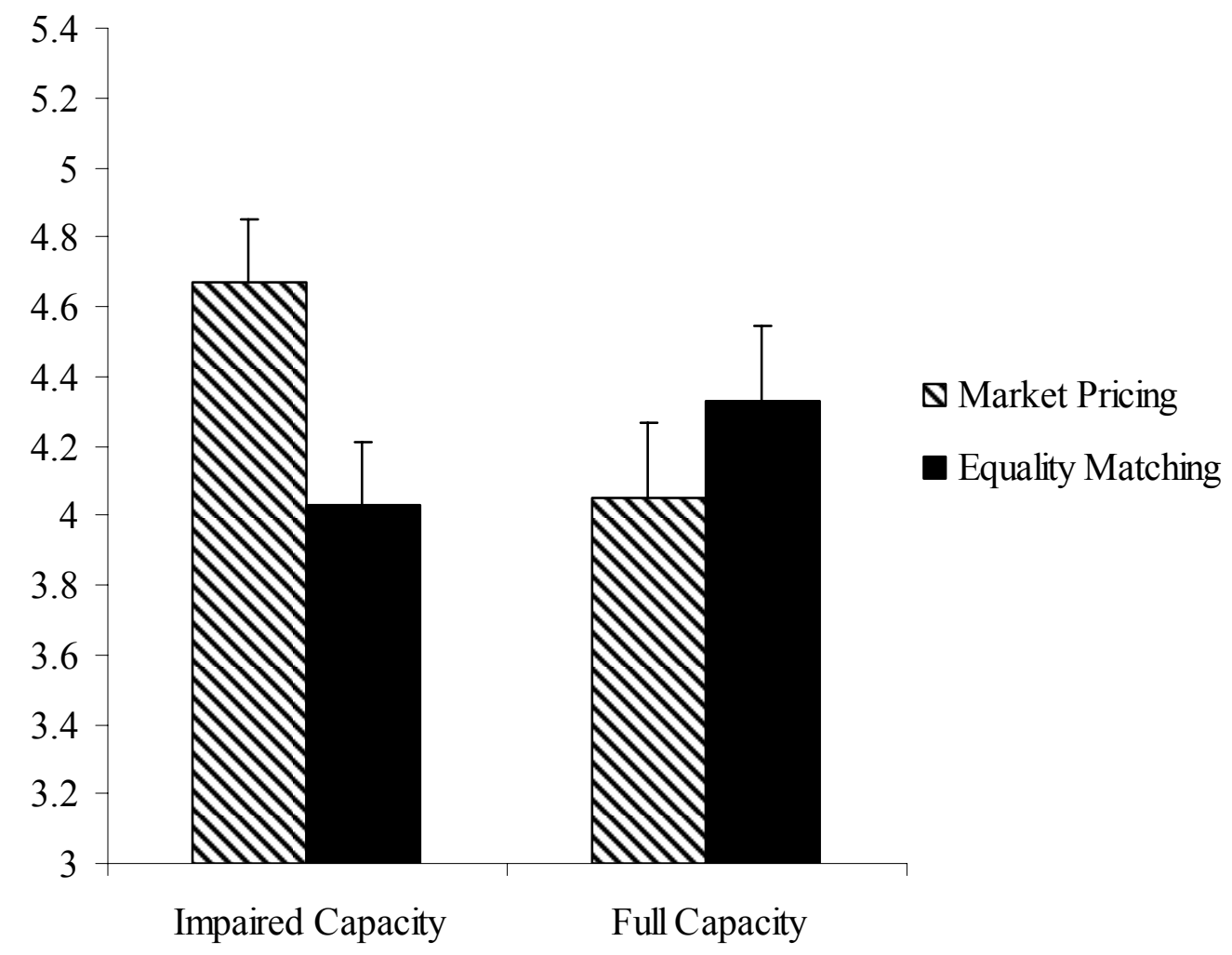


Figure 2

Compliance as Function of Relationship and Cognitive Capacity, Study 1

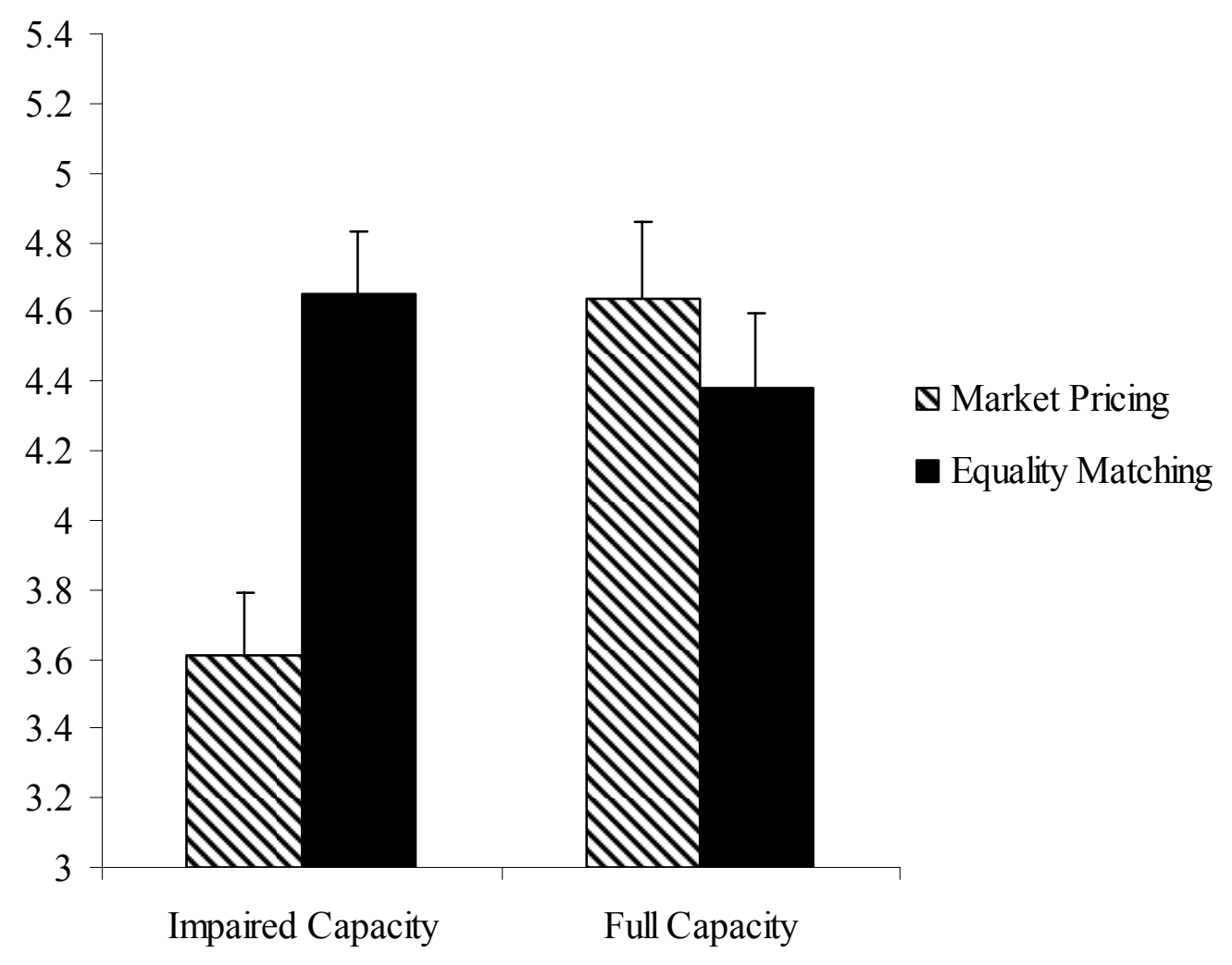


Figure 3

Perceived Sincerity as Function of Disclosure and Cognitive Capacity, Study 2

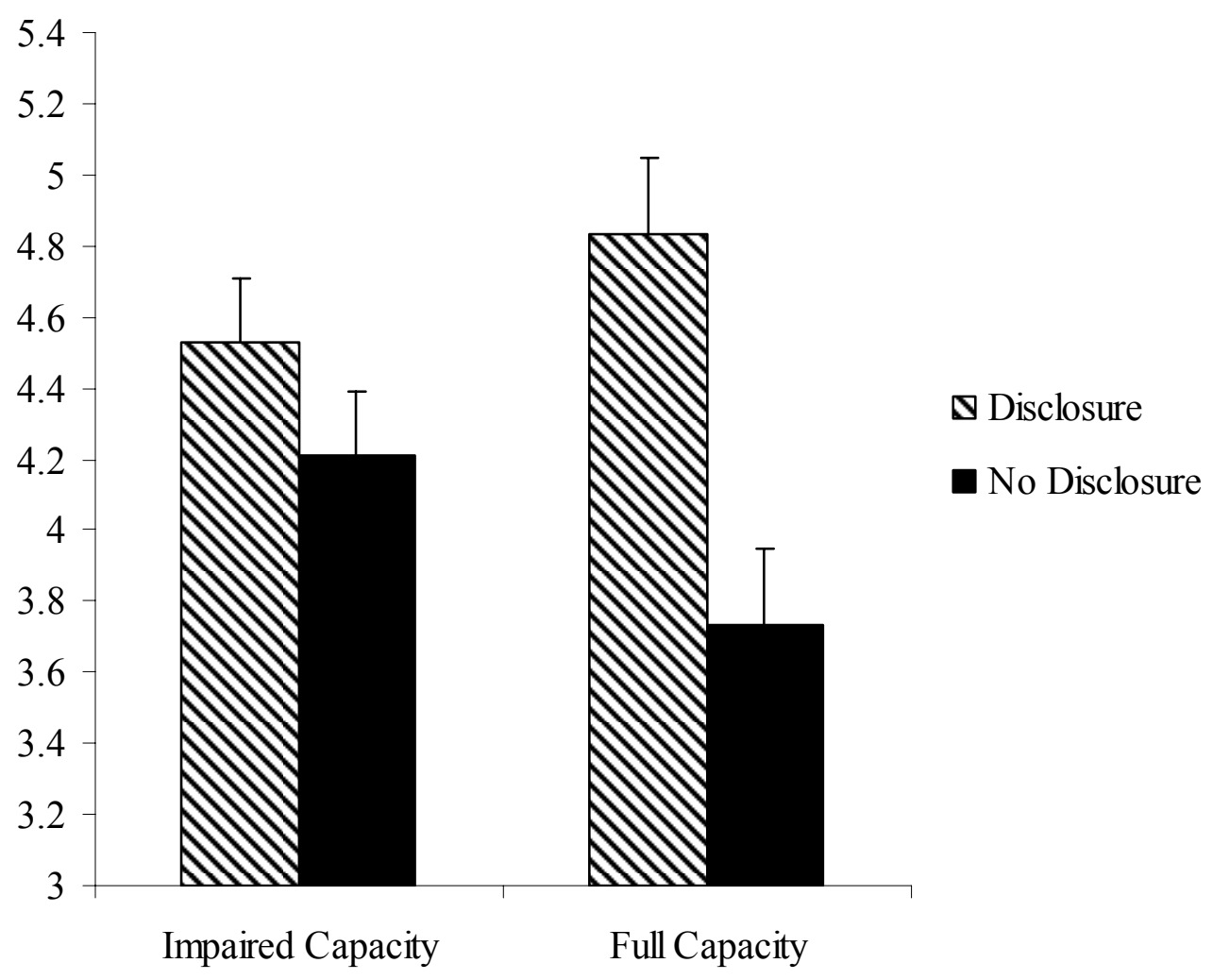




\section{Publications in the Report Series Research ${ }^{*}$ in Management}

\section{ERIM Research Program: "Marketing"}

2008

Experts' Stated Behavior

Youssef Boulaksil and Philip Hans Franses

ERS-2008-001-MKT

http://hdl.handle.net/1765/10900

The Value of Analogical Reasoning for the Design of Creative Sales Promotion Campaigns: A Case-Based Reasoning Approach

Niek A.P. Althuizen and Berend Wierenga

ERS-2008-006-MKT

http://hdl.handle.net/1765/11289

Shopping Context and Consumers' Mental Representation of Complex Shopping Trip Decision Problems Benedict G.C. Dellaert, Theo A. Arentze and Harry J.P. Timmermans ERS-2008-016-MKT

http://hdl.handle.net/1765/11812

Modeling the Effectiveness of Hourly Direct-Response Radio Commercials

Meltem Kiygi Calli, Marcel Weverbergh and Philip Hans Franses

ERS-2008-019-MKT

http://hdl.handle.net/1765/12242

Choosing Attribute Weights for Item Dissimilarity using Clikstream Data with an Application to a Product Catalog Map Martijn Kagie, Michiel van Wezel and Patrick J.F. Groenen

ERS-2008-024-MKT

http://hdl.handle.net/1765/12243

The Effect of Superstar Software on Hardware Sales in System Markets

Jeroen L.G. Binken and Stefan Stremersch

ERS-2008-025-MKT

http://hdl.handle.net/1765/12339

Sales Growth of New Pharmaceuticals Across the Globe: The Role of Regulatory Regimes

Stefan Stremersch and Aurélie Lemmens

ERS-2008-026-MKT

http://hdl.handle.net/1765/12340

When Intelligence is (Dys)Functional for Achieving Sales Performance

Willem J. Verbeke, Frank D. Belschak, Arnold B. Bakker, and Bart Dietz

ERS-2008-034-MKT

http://hdl.handle.net/1765/12633

Path Dependencies and the Long-term Effects of Routinized Marketing Decisions

Paul Farris, Willem J. Verbeke, Peter Dickson and Erjen van Nierop

ERS-2008-035-MKT

http://hdl.handle.net/1765/12634

Does Irritation Induced by Charitable Direct Mailings Reduce Donations?

Merel van Diepen, Bas Donkers and Philip Hans Franses

ERS-2008-036-MKT

http://hdl.handle.net/1765/12704 
Brain Mechanisms of Persuasion: How "Expert Power" Modulates Memory and Attitudes

Vasily Klucharev, Ale Smidts and Guillén Fernández

ERS-2008-038-MKT

http://hdl.handle.net/1765/12784

Moderating Factors of Immediate, Dynamic, and Long-run Cross-Price Effects

Csilla Horváth and Dennis Fok

ERS-2008-042-MKT

http://hdl.handle.net/1765/12901

Why, How and When Do Prices Land? Evidence from the Videogame Industry

Carlos Hernandez-Mireles, Dennis Fok and Philip Hans Franses

ERS-2008-044-MKT

http://hdl.handle.net/1765/12900

Situation-Based Shifts in Consumer Web Site Benefit Salience: The Joint Role of Affect and Cognition

Sonja Wendel and Benedict G.C. Dellaert

ERS-2008-050-MKT

http://hdl.handle.net/1765/13179

Including Item Characteristics in the Probabilistic Latent Semantic Analysis Model for Collaborative Filtering

Martijn Kagie, Matthijs van der Loos and Michiel van Wezel

ERS-2008-053-MKT

http://hdl.handle.net/1765/13180

Cross-National Logo Evaluation Analysis: An Individual Level Approach

Ralf van der Lans, Joseph A. Cote, Catherine A. Cole, Siew Meng Leong, Ale Smidts, Pamela W. Henderson, Christian Bluemelhuber, Paul A. Bottomley, John R. Doyle, Alexander Fedorikhin, M. Janakiraman, B. Ramaseshan,

and Bernd $H$. Schmitt

ERS-2008-055-MKT

http://hdl.handle.net/1765/13181

Sales and Sincerity: The Role of Relational Framing in Word-of-Mouth Marketing

Mirjam A. Tuk, Peeter W.J. Verlegh, Ale Smidts and Daniel H.J. Wigboldus

ERS-2008-056-MKT

http://hdl.handle.net/1765/13183

Interpersonal Relationships Moderate the Effect of Faces on Person Judgments

Mirjam A. Tuk, Peeter W.J. Verlegh, Ale Smidts and Daniel H.J. Wigboldus

ERS-2008-057-MKT

http://hdl.handle.net/1765/13185

\footnotetext{
A complete overview of the ERIM Report Series Research in Management: https://ep.eur.nl/handle/1765/1

ERIM Research Programs:

LIS Business Processes, Logistics and Information Systems

ORG Organizing for Performance

MKT Marketing

F\&A Finance and Accounting

STR Strategy and Entrepreneurship
} 